\title{
Analysis of gene function in somatic mammalian cells using small interfering RNAs
}

\author{
Sayda M. Elbashir, ${ }^{\mathrm{a}, 1}$ Jens Harborth, ${ }^{\mathrm{b}, 1}$ Klaus Weber, ${ }^{\mathrm{b}, *}$ and Thomas Tuschl ${ }^{\mathrm{a}, *}$ \\ a Department of Cellular Biochemistry, Max-Planck-Institute for Biophysical Chemistry, Am Fassberg 11, D-37077 Göttingen, Germany \\ ${ }^{\mathrm{b}}$ Department of Biochemistry and Cell Biology, Max-Planck-Institute for Biophysical Chemistry, Am Fassberg 11, D-37077 Göttingen, Germany
}

Accepted 29 January 2002

\begin{abstract}
RNA interference (RNAi) is a highly conserved gene silencing mechanism that uses double-stranded RNA (dsRNA) as a signal to trigger the degradation of homologous mRNA. The mediators of sequence-specific mRNA degradation are 21- to 23-nt small interfering RNAs (siRNAs) generated by ribonuclease III cleavage from longer dsRNAs. Twenty-one-nucleotide siRNA duplexes trigger specific gene silencing in mammalian somatic cells without activation of the unspecific interferon response. Here we provide a collection of protocols for siRNA-mediated knockdown of mammalian gene expression. Because of the robustness of the siRNA knockdown technology, genomewide analysis of human gene function in cultured cells has now become possible. ( 2002 Elsevier Science (USA). All rights reserved.
\end{abstract}

Keywords: RNA interference; Small interfering RNA; Posttranscriptional gene silencing; Knockdown; Double-stranded RNA

\section{Introduction}

Mammalian gene function has been determined traditionally by methods such as disruption of murine genes, the introduction of transgenes, the molecular characterization of human hereditary diseases, and targeting of genes by antisense or ribozyme techniques. In addition, microinjection of specific antibodies into cultured cells or binding of antibodies to cell surface-exposed receptors may provide information on the function of the targeted protein. A new alternative to these reverse genetic approaches has now become available with the discovery of small interfering RNAs, which are able to trigger RNA interference in mammalian somatic cells $[1,2]$.

RNA interference (RNAi) is a sequence-specific posttranscriptional gene silencing mechanism, which is triggered by double-stranded RNA and causes degradation of mRNAs homologous in sequence to the

\footnotetext{
${ }^{*}$ Corresponding authors. Fax: +49-551-201-1197.

E-mail addresses: office.weber@mpibpc.gwdg.de (K. Weber), ttuschl@mpibpc.gwdg.de (T. Tuschl).

${ }^{1}$ Authors contributed equally to this review.
}

dsRNA [3,4]. Although RNAi has been observed in a wide range of eukaryotes, including plants, protists, filamentous fungi, and invertebrate and vertebrate animals [5-10], it has only recently become possible to silence human genes in cultured somatic cells [1]. The detection of RNAi in somatic mammalian cells has been hampered by the presence of a number of dsRNA-triggered pathways that mediate nonspecific suppression of gene expression [11-14]. dsRNA is a potent inducer of type I interferon (IFN) synthesis and is the activator of two classes of IFN-induced enzymes: PKR, the dsRNA-dependent protein kinase, and $2^{\prime}, 5^{\prime}$-oligoadenylate synthetases, whose products activate the latent ribonuclease RNase L. These nonspecific responses to dsRNA are not triggered by dsRNA shorter than $30 \mathrm{bp}$ including siRNA duplexes that resemble in length and structure the natural processing products from long dsRNAs $[1,2,15]$. The most predominant processing products are duplexes of 21- and 22-nt RNAs with symmetric 2-nt $3^{\prime}$ overhangs, which are also the most efficient mediators of mRNA degradation [16].

One of the enzymes involved in processing long dsRNAs to siRNA duplexes is the RNase III enzyme Dicer, which was characterized in extracts prepared 
from insect cells [17], Caenorhabditis elegans embryos [18], and mammalian cultured cells [19]. In mammalian cells, it was also shown that Dicer localizes to the cytoplasm, which provides evidence that RNAi is a predominantly cytoplasmic process [19]. Dicer has an Nterminal RNA helicase domain, a PAZ domain [20], two RNase III domains, and a C-terminal dsRNA-binding motif. A PAZ domain is also present in Argonaute2, which is a component of the mRNA-degrading sequence-specific endonuclease complex of Drosophila melanogaster Schneider 2 cells [21]. This siRNA-bound endonuclease complex was also referred to as RNA-induced silencing complex (RISC) [22]. Dicer and Argonaute2 appear to interact in S2 cells, probably through their PAZ domains, but RISC and Dicer activities could be separated and RISC was unable to process dsRNA to siRNAs, suggesting that Dicer is not a component of RISC $[21,22]$. Possibly, the interaction between Dicer and Argonaute 2 facilitates siRNA incorporation into RISC [21]. The catalytic subunit of RISC remains to be identified. A schematic illustration of the mechanism of RNAi is shown in Fig. 1.

In $D$. melanogaster lysate, RISC is readily assembled onto synthetic siRNA duplexes and is highly effective in degrading homologous mRNAs $[16,23]$. In vivo, siRNA duplexes are easily introduced into $D$. melanogaster or human somatic cells by transfection with cationic liposomes [1]. When siRNAs are directed against endogenous genes, expression of the corresponding gene

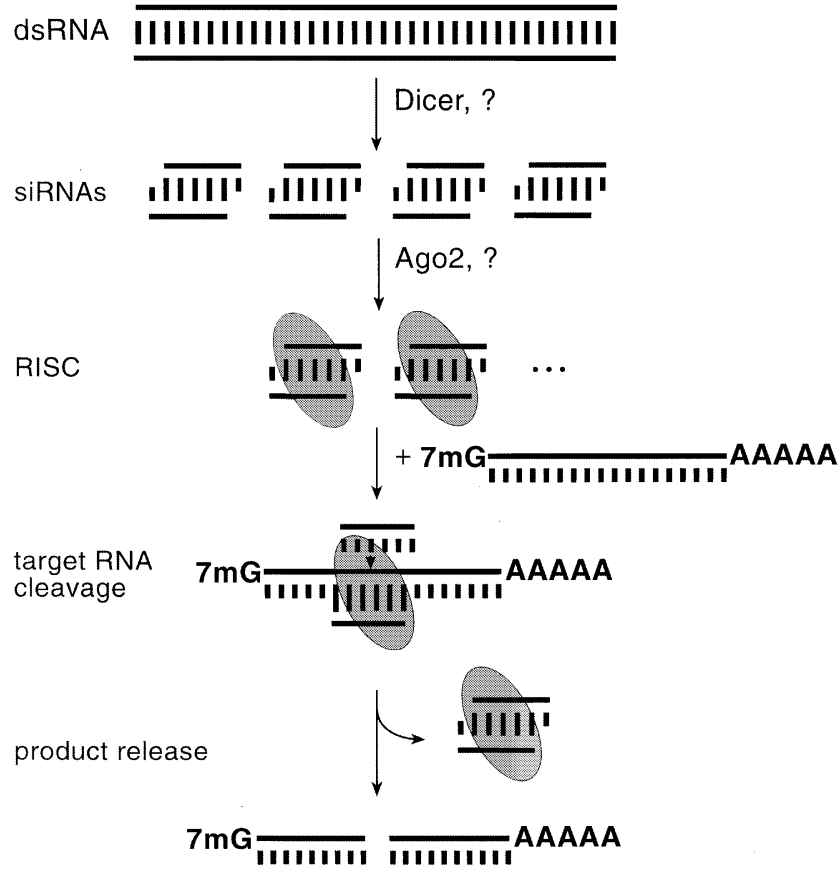

Fig. 1. Model for RNA interference. dsRNA is processed to 21- to 23nt siRNA duplexes by Dicer RNase III and presumably other factors. The siRNA duplexes are incorporated into RISC, which targets homologous mRNAs for degradation. Ago2 and yet to be characterized proteins participate in RISC formation. products is knocked down as expected. This technique can be applied to any protein-coding gene, as validated recently by examining the knockdown phenotypes of 20 different gene products in human somatic cells [24]. In a different report, siRNAs were successfully used to knockdown human Dicer protein, which revealed a new cellular function of Dicer for let-7 RNA precursor processing [25]. Furthermore, siRNAs were successfully used to establish a function for the human vacuolar protein Tsg101 for HIV (human immunodeficiency virus) budding [26]. Knockdown of this cellular protein arrested HIV-1 budding and this defect could be rescued by transfection of a plasmidborne, RNAi-resistant version of Tsgl01. This combination of siRNA knockdown and plasmid rescue experiments will become extremely valuable for functional analysis of mutant protein-coding constructs. Further applications of siRNAs for specific gene silencing in cultured mammalian cells have been published recently [15,27-31].

Here we present detailed protocols to produce and evaluate siRNA-induced protein knockdowns in mammalian somatic cells. The method is useful for reverse genetic analysis of mammalian gene function in any aspect of general cell biology, such as cell cycle, gene expression, metabolic pathways, or the cytoskeleton. The method is also suitable for high-throughput analysis of gene function, provided that highly transfectable cell lines are used and that single-cell based assays, e.g., immunofluorescence, are applied for phenotypic screening.

\section{Selection of siRNA sequences for targeting of mRNAs}

The design of siRNA duplexes for interfering with the expression of a specific gene requires knowledge of the accurate target sequence, i.e., of at least a 20 -nt segment of its encoded mRNA. Intronic sequences contained in pre-mRNAs should not be targeted, because incompletely spliced mRNAs are normally retained in the nucleus and RNAi is believed to occur predominantly, if not exclusively, in the cytoplasm. Sequence information about mature mRNAs may be extracted from EST databases (www.ncbi.nlm.nih.gov or www.ebi.ac.uk) or can be predicted from genomic sequences using gene prediction programs. However, the limited quality of single-pass EST sequence data or gene predictions should be kept in mind.

The analysis of siRNA function in D. melanogaster embryo lysates indicated that siRNA duplexes composed of 21-nt sense and 21-nt antisense strands, paired in a manner to have a 2-nt $3^{\prime}$ overhang, are the most efficient triggers of sequence-specific mRNA degradation in this system [23]. Preliminary analysis of the length dependence of siRNAs in mammalian cells suggests that this may also be true in mammalian systems, although differences in efficiencies as a function of 
siRNA length are less pronounced than in the fly biochemical system (Ref. [2], and Section 4).

The target RNA cleavage reaction guided by siRNAs is highly sequence-specific. However, not all positions of a siRNA contribute equally to target recognition [23]. Mismatches in the center of the siRNA duplex are most critical and essentially abolish target RNA cleavage. In contrast, the $3^{\prime}$ nucleotide of the siRNA strand (position 21) that is complementary to the single-stranded target RNA does not contribute to specificity of target recognition. As may be expected, the sequence of the unpaired 2-nt $3^{\prime}$ overhang of the siRNA strand with the same polarity as the target RNA is not critical for target RNA cleavage as only the antisense siRNA strand guides target recognition. Thus, only the penultimate position of the antisense siRNA (position 20) needs to match the targeted sense mRNA [23].

Selection of the targeted region is currently a trialand-error process, but with the likelihood of $80-90 \%$ success given a large enough random selection of target genes [24]. In every single case, however, the half-life of the targeted gene product, its abundance, or the regulation of its expression may have to be considered. For example, in an attempt to knock down the strongly expressed and stable intermediate filament protein vimentin, only two of four randomly selected siRNAs were effective [24]. We prefer to select target regions such that siRNA sequences may contain uridine residues in the 2-nt overhangs (Fig. 2A). Uridine residues in the 2 -nt $3^{\prime}$ overhang can be replaced by $2^{\prime}$-deoxythymidine without loss of activity, which significantly reduces costs of RNA synthesis and may also enhance nuclease resistance of siRNA duplexes when applied to mammalian cells [23]. Another rationale for designing siRNA duplexes with symmetric TT overhangs is to ensure that the sequence-specific endonuclease complex (RISC) is formed with an approximately equal ratio of sense to antisense target RNA-cleaving complexes [16,23].

It may also be desirable to design siRNA sequences in a manner that may allow the later expression of siRNAs from plasmids or in transgenic animals, should such technology become available. Efficient expression of small ribozymes or antisense RNAs using polymerase III promoters was previously demonstrated $[32,33]$. Because RNA transcription is primed by $5^{\prime}$-guanosine triphosphate, it would require the selection of siRNA sequences starting with $5^{\prime}$-guanosine residues.

It was recently demonstrated that a $5^{\prime}$-phosphate on the target-complementary strand of a siRNA duplex is required for siRNA function and that ATP is used to maintain the $5^{\prime}$-phosphates of the siRNAs [34]. However, siRNA duplexes with free $5^{\prime}$-hydroxyls and 2-nt $3^{\prime}$ overhangs are readily phosphorylated in D. melanogaster embryo lysates [34] and also in extracts prepared from human HeLa cells (J. Martinez and T. Tuschl, unpublished). As expected, comparison of the mammalian RNAi efficiencies of 5'-phosphorylated and nonphosphorylated siRNAs did not reveal any sizable differences (J. Harborth, S. Elbashir, unpublished). Thus, siRNAs synthesized or purchased without a $5^{\prime}$-phosphate group can be used in knockdown experiments.

Finally, we believe that the secondary structure of the target mRNA does not have a strong effect on silencing, as judged by the success rate of the essentially randomly chosen siRNA duplexes. A more comprehensive evaluation of all the parameters to be considered for siRNA selection remains to be performed, perhaps best on a therapeutically relevant target. Therefore, our
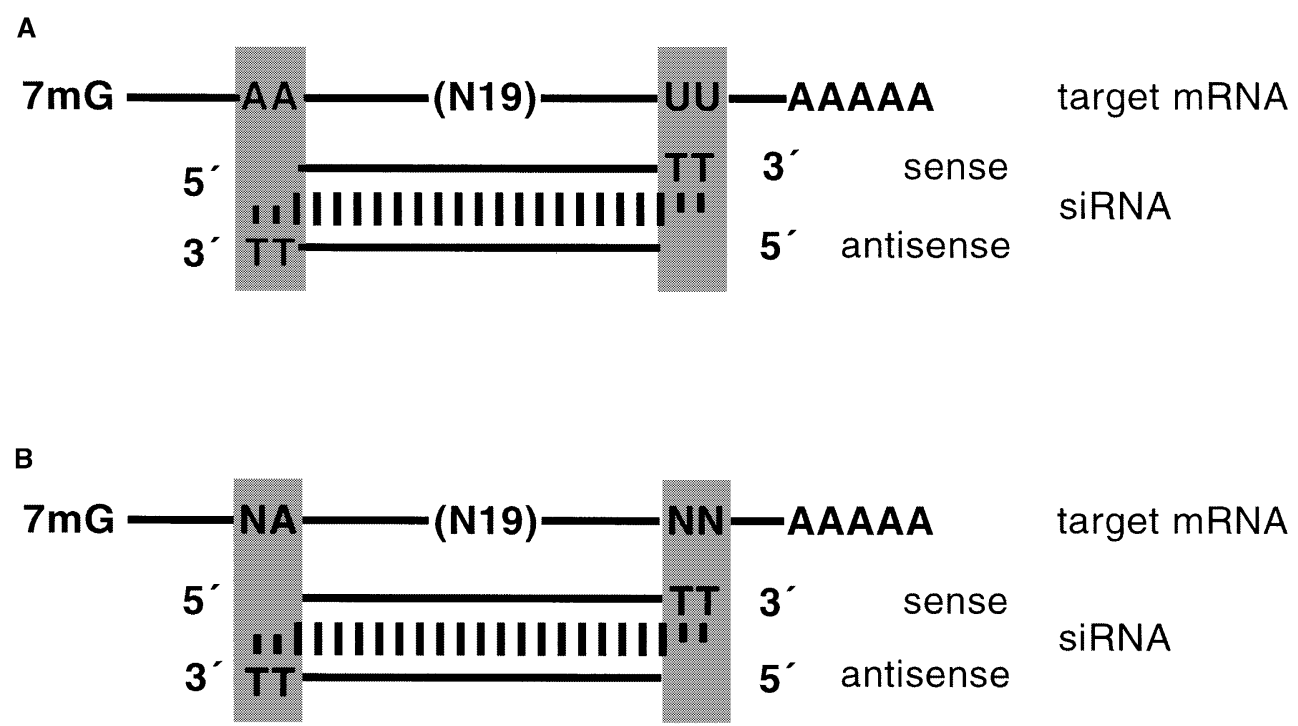

Fig. 2. Selection of siRNA duplexes. (A) The design of siRNA duplexes for target mRNAs that contain the sequence AA(N19)UU. (B) The design of siRNA duplexes in the absence of AA(N19)UU target sequences. As long as one adenosine is present in the targeted region, siRNA duplexes with $3^{\prime}-$ TT overhangs can be used without effect on specificity of target recognition or RNAi efficiency. 
"personal" set of rules is only a historic starting point and it is not intended to discourage anybody from further experimentation.

\subsection{Protocol 1: selection of siRNA sequences}

1. Select the target region from the open reading frame of a given cDNA sequence preferably 50 to $100 \mathrm{nt}$ downstream of the start codon. Avoid $5^{\prime}$ or $3^{\prime}$ untranslated regions (UTRs) or regions close to the start codon as these may be richer in regulatory protein binding sites. It is conceivable that UTR-binding proteins and/or translation initiation complexes could interfere with binding of RISC to the target RNA. However, if it is desired to rescue a knockdown phenotype by reintroduction of a plasmid coding for a mutant or tagged form of the targeted gene, it may be favorable to target regions in the UTRs. Preparation of rescue constructs by deletion of terminal untranslated sequences is easier than the introduction of silent mutations within the targeted region of a coding segment. Which of the approaches works best remains to be examined.

2. Search for sequences $5^{\prime}$-AA(N19)UU, where $N$ is any nucleotide, in the mRNA sequence and choose those with approximately 50\% G/C content (Fig. 2A). Nevertheless, 32 to $79 \% \mathrm{G} / \mathrm{C}$ content has also worked well in our hands. Highly G-rich sequences should be avoided because they tend to form Gquartet structures. If there are no $5^{\prime}-\mathrm{AA}(\mathrm{N} 19) \mathrm{UU}$ motifs present in the target mRNA, search for $5^{\prime}$ $\mathrm{AA}(\mathrm{N} 21)$ or $5^{\prime}-\mathrm{NA}(\mathrm{N} 21)$ (Fig. 2B). Independent of the selection procedure described in Fig. 2, synthesize the sense siRNA as $5^{\prime}$-(N19)TT, and the sequence of the antisense siRNA as $5^{\prime}-\left(\mathrm{N}^{\prime} 19\right) \mathrm{TT}$, where $\mathrm{N}^{\prime} 19$ denotes the reverse complement sequence of N19. N19 and N'19 indicate ribonucleotides; $\mathrm{T}$ indicates $2^{\prime}$-deoxythymidine.

3. Blast-search (www.ncbi.nlm.nih.gov/BLAST) the selected siRNA sequences against EST libraries or mRNA sequences of the respective organism to ensure that only a single gene is targeted.

4. It may be advisable to synthesize several siRNA duplexes to control for the specificity of the knockdown experiments; those siRNA duplexes that are effective for silencing should produce exactly the same phenotype. Furthermore, a nonspecific siRNA duplex may be needed as control. It is possible to reverse the sequence of an effective siRNA duplex or to use a siRNA duplex, which is targeting a gene absent from the selected model organism, e.g., GFP or luciferase. We have previously used a siRNA duplex targeting firefly luciferase as a control for targeting endogenous genes in mammalian cells since the firefly luciferase gene was not present in the targeted cells [1].
5. If the siRNA does not work, first verify that the target sequence and the cell line used are derived from the same organism. According to a recent study, there is quite a high probability for not having the right cell line [35]. Finally, make sure that the mRNA sequence used for selection of the siRNA duplexes is reliable; it could contain sequencing errors, mutations (e.g., in cancer cells) or polymorphisms.

\section{Preparation of siRNA duplexes}

Twenty-one-nucleotide RNAs are preferably chemically synthesized using appropriately protected ribonucleoside phosphoramidites and a conventional DNA/ RNA synthesizer. Synthesis protocols are adapted to RNA reagents [36]. Suppliers of RNA synthesis reagents are Proligo (Hamburg, Germany, www.proligo.com), Dharmacon Research (Lafayette, CO, www.dharmacon.com), Pierce Chemical (part of Perbio Science, Rockford, IL, www.perbio.com), Glen Research (Sterling, VA, www.glenres.com), ChemGenes (Ashland, MA, www.chemgenes.com), and Cruachem (Glasgow, UK, www.cruachem.com). Most conveniently, siRNAs are obtained from commercial RNA oligonucleotide synthesis suppliers, which sell RNA synthesis products of different quality and costs. In general, 21-nt RNAs are not too difficult to synthesize and are readily provided in a quality suitable for RNAi.

The following custom RNA synthesis companies are entitled to provide siRNAs with a license for target validation. A typical $0.2-\mu$ mol-scale RNA synthesis provides about $1 \mathrm{mg}$ of RNA, which is sufficient for 1000 transfection experiments using a 24-well tissue culture plate format.

\subsubsection{Dharmacon (www.dharmacon.com)}

Dharmacon currently offers three siRNA options for the custom synthesis of siRNA oligonucleotides. (Dharmacon also offers a range of presynthesized siRNA duplexes.) Option A offers water-soluble, stable, 2 '-protected RNA, which is readily deprotected in aqueous buffers after arrival. The $2^{\prime}$ protection ensures the RNA is not degraded before use. The pair of RNA oligonucleotides can be simultaneously $2^{\prime}$-deprotected and annealed in the same reaction as a further precaution against degradation. The siRNA duplex can then be readily desalted via ethanol precipitation directly from the aqueous 2'-deprotection/annealing reaction [37]. After deprotection and annealing, the RNA pellet is dissolved in $400 \mu \mathrm{l}$ buffer. To ethanol precipitate, adjust the solution to $0.3 \mathrm{M} \mathrm{NaCl}$ by addition of $26 \mu \mathrm{l} 5 \mathrm{M}$ $\mathrm{NaCl}$. Finally, add $1500 \mu \mathrm{l}$ absolute ethanol and vortex. After 1-2 $h$ incubation of the sample on dry ice or at -20 ${ }^{\circ} \mathrm{C}$, collect the RNA pellet by centrifugation. Remove all 
liquid and redissolve the pellet in 200-400 $\mu$ sterile water. Determine the concentration by UV spectroscopy ( $1 A_{260}$ unit is equivalent to $32 \mu \mathrm{g}$ RNA) and continue with annealing (see below). Alternatively, the pair of RNA oligonucleotides can be simultaneously $2^{\prime}$-deprotected and annealed in the same reaction as a further precaution against degradation. The siRNA duplex can then be readily desalted via ethanol precipitation directly from the aqueous $2^{\prime}$-deprotection/annealing reaction [37]. It should be noted that the crude RNA products are more than $85 \%$ full-length, which makes gel purification of siRNAs for knockdown applications unnecessary. Option B provides the RNA fully deprotected, desalted, and aliquoted in 50-nmol amounts. Redissolve the shipped RNA pellet in water and continue with siRNA annealing (see below). Option C provides the siRNAs as the purified duplex with a purity $>97 \%$. Redissolve the shipped RNA duplex pellet in water and continue directly with transfection (see below). This final option guarantees the duplex is properly formed and ready for transfection. It is also possible to order the RNA with duplexing but no purification with either Option A or Option B.

\subsubsection{Xeragon Inc. (www.xeragon.com)}

Xeragon offers siRNAs in two ready-to-use options and a variety of off-the-shelf siRNA duplexes for common gene targets. Option 1 offers crude siRNAs that are fully deprotected and desalted (NAP-10 Sephadex G-25 and ethanol precipitation) and which are more than $85 \%$ pure. Option 2 provides siRNAs that are ion-exchange HPLC-purified and are more than $97 \%$ pure. Both options include a choice for free annealing and come with a quality HPLC-trace done on the actual duplex if annealing was requested. Otherwise the quality is shown in two individual chromatograms. Both options are ready for transfection. The sterile buffer to dilute the siRNAs is provided. It is recommended that siRNA duplexes lyophilized for shipment be dissolved in annealing buffer and reheated to $95^{\circ} \mathrm{C}$ for $1 \mathrm{~min}$ followed by $1 \mathrm{~h}$ at $37^{\circ} \mathrm{C}$ incubation (as described below). This procedure disrupts higher aggregates, which may have formed in the lyophilization process.

\subsubsection{Genset Oligos (www.gensetoligos.com)}

Genset Oligos offers fully deprotected and desalted siRNAs delivered in dried form and ready for resuspension. The siRNAs are supplied in either single strand or duplex format and are more than $85 \%$ pure. Genset Oligos also offers siRNAs at higher grades of purity (PAGE, RP-HPLC purification). All shipped siRNAs are systematically controlled by PAGE and certified for gene silencing applications. The protocol for siRNA annealing is posted on Genset Oligo's Web site.

\subsubsection{Ambion (www.ambion.com)}

Ambion has developed a transcription-based method for construction of siRNA available as The Silencer siRNA Construction Kit. Ambion also offers the traditional custom chemical synthesis service for siRNA and supplies fully deprotected and desalted siRNAs, with optional PAGE purification and delivered in dry form along with RNase-free water and $5 \times$ annealing buffer. A central Web-based resource for RNAi and siRNA methodologies, along with links to additional siRNA-related products and services, can be found on Ambion's Web site.

Several other synthesis companies may provide 21-nt RNAs without a license for siRNA applications. However, it should be noted that the application of RNAs as siRNAs requires a license, which is included when purchasing RNA from licensed providers listed above, or can be provided as in-house research licenses from the MIT licensing office (Cambridge, MA) or Garching Innovation (Munich, Germany).

\subsection{Protocol 2: annealing of siRNAs to produce siRNA duplexes}

1. Prepare $2 \times$ annealing buffer $(200 \mathrm{mM}$ potassium acetate, $4 \mathrm{mM}$ magnesium acetate, $60 \mathrm{mM}$ Hepes$\mathrm{KOH}, \mathrm{pH}$ 7.4).

2. To prepare $140 \mu \mathrm{l}$ of a $20 \mu \mathrm{M}$ siRNA duplex solution, combine $70 \mu \mathrm{l} 2 \times$ annealing buffer, $x \mu$ l sense siRNA ( $20 \mu \mathrm{M}$ final concentration), $y \mu \mathrm{l}$ antisense oligonucleotide $(20 \mu \mathrm{M}$ final concentration), and $70-x-y \mu$ sterile water.

3. Incubate for $1 \mathrm{~min}$ at $90{ }^{\circ} \mathrm{C}$, followed by $1 \mathrm{~h}$ at 37 ${ }^{\circ} \mathrm{C}$. After use, store the solution frozen at $-20{ }^{\circ} \mathrm{C}$. The siRNA duplex solution can be freeze-thawed many times and does not require any further heatshock treatments. As general advice, it is recommended that RNA solutions be kept on ice as much as possible to reduce the rate of RNA hydrolysis.

4. For quality control, separately load $1 \mu \mathrm{l} 20 \mu \mathrm{M}$ sense and antisense siRNA and $0.5 \mu 120 \mu \mathrm{M}$ siRNA duplex onto $4 \%$ NuSieve GTG agarose gels (BMA, Rockland, ME, www.bmaproducts.com). For loading of the samples, it is helpful to first dilute the samples with a few microliters of $0.5 \times$ TBE buffer $(45 \mathrm{mM}$ Tris base, $45 \mathrm{mM}$ boric acid, $1 \mathrm{mM} \mathrm{Na} 2$ EDTA) and sucrose loading buffer [38]. Run the gel in $0.5 \times$ TBE buffer at $80 \mathrm{~V}$ for $1 \mathrm{~h}$. Note that NuSieve agarose is a low-melt agarose and it may melt if electrophoresis is performed with too high an electric current. The RNA bands are visualized under UV light after ethidium bromide staining. Preferably, the ethidium bromide is added to the $4 \%$ gel $/ 0.5 \times \mathrm{TBE}$ solution at a concentration of $0.04 \% \mathrm{mg} / 1$ prior to casting of the gel. An example is illustrated in Fig. 3. 


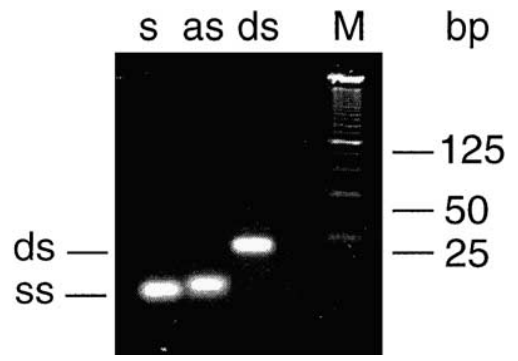

Fig. 3. Analysis of siRNA duplex formation. Single-stranded (ss) sense RNA (s), antisense RNA (as), and annealed siRNA duplexes (ds) were separated on $4 \%$ NuSieve agarose gels. A 25-bp DNA ladder (M) was loaded as marker. The bands were visualized by UV light after ethidium bromide staining. The siRNA duplex was used for targeting la$\min \mathrm{A} / \mathrm{C}$ mRNA [1].

\section{Determination of RNAi activity of mammalian cells by co-transfection of luciferase reporter plasmids and siRNA duplexes}

Before siRNAs are applied to knock down an endogenous gene, it may be important to establish if the studied cells are susceptible to RNAi. It may be possible that some cell lines have lost the ability to perform RNAi or that cells derived from certain tissues do not support RNAi. We developed a rapid and reliable protocol to examine transfectable cell lines for the ability to perform RNAi [1]. Reporter plasmids, encoding firefly (Photinus pyralis) and sea pansy (Renilla reniformis) luciferase (Fig. 4A), were cotransfected into cells with specific or control siRNAs (Fig. 4B). Following a 1-day incubation period, cells were lysed and luciferase activity was monitored. The sensitive luciferase assay combined with the siRNA cotransfection provide a reliable readout even at low transfection efficiencies. Using this assay, we demonstrated that siRNAs trigger silencing in HeLa (human cervix carcinoma) S3 (Fig. 4C, D) and HeLa SS6, COS-7 (African green monkey kidney), NIH/ 3T3 (mouse fibroblast), HEK 293 (human embryonic kidney), $\mathrm{CHO}$ (Chinese hamster ovary) (Fig. 4E), A431 (human epidermoid carcinoma) (Fig. 4F), and SKBR3 (human breast tumor) (Fig. 4G) cells. Instead of luciferase constructs, green fluorescent protein (GFP)-encoding plasmids may be transfected together with GFP and control siRNAs. The GFP-based assay may be most suitable for quantification by fluorescence-activated cell sorting (FACS). Please note that transfection reagents change the autofluorescence of cells, which must be controlled for by mock transfection.

\subsection{Protocol 3: cell culture and preparation of cells in 24- well plates}

1. Grow various mammalian cell lines, e.g., HeLa S3, HeLa SS6, COS7, NIH/3T3, HEK 293, CHO, $\mathrm{A} 431$, and SKBR3, in a $5 \% \mathrm{CO}_{2}$ humidified incubator at $37^{\circ} \mathrm{C}$ in Dulbecco's modified Eagle's medium
(DMEM) (Life Technologies, No. 41966-029, www.lifetech.com) supplemented with $10 \%$ fetal bovine serum (FBS) (Life Technologies, No. 10500-064), 100 units $/ \mathrm{ml}$ penicillin, and $100 \mu \mathrm{g} / \mathrm{ml}$ streptomycin (BioChrom, No. A2212, www.biochrom.com). For general advice on cell culture, see [39]. Passage cells regularly to maintain exponential growth. Do not exceed a passage number of 30 after thawing the stock culture. The number of passages may affect DNA and siRNA transfection efficiencies. Aliquots of cells of low passage number may be stored frozen and can be thawed at convenience.

2. One day $(24 \mathrm{~h})$ before plasmid/siRNA transfection, trypsinize $90 \%$ confluent cells grown in a $175-\mathrm{ml}$ cell culture flask with $10 \mathrm{ml}$ trypsin-EDTA (Life Technologies, No. 25300-054). Dilute the cell suspension 1:5 with fresh DMEM medium without antibiotics, and transfer $500-\mu 1$ aliquots into each well of a 24well plate. If immunofluorescence assays are planned, cells should be grown on coverslips, which are placed at the bottom of the 24-well plates prior to addition of the cell suspension. Twenty-four hours after seeding the cells, a confluency of 50 $80 \%$ should be reached, which corresponds to $3 \times 10^{4}-1 \times 10^{5}$ cells per well depending on the cell line and its doubling time.

\subsection{Protocol 4: cotransfection of luciferase reporter plasmids with siRNA duplexes}

The protocol below is based on a published procedure [1]. Two applications are illustrated in Figs. 4 and 5 . The quantities of reagents given below are calculated for the transfection of one well of a 24-well plate.

1. The day before transfection, follow protocol 3 for culturing cells in 24-well plates.

2. Mix 1.0 $\mu \mathrm{g}$ pGL2-Control plasmid (Promega, No. E1611) or $1 \mu \mathrm{g}$ pGL3-Control plasmid (Promega, No. E1741) with $0.1 \mu \mathrm{g}$ pRL-TK plasmid (Promega, No. E2241, www.promega.com) and $0.21 \mu \mathrm{g}$ siRNA duplex $(0.75 \mu 120 \mu \mathrm{M}$ annealed duplex, see protocol 2) with $50 \mu$ OPTI-MEM 1 medium (Life Technologies, No. 31985-047). Reporter plasmids may be amplified in XL-1 Blue (Stratagene, No. 200249, www.stratagene.com) and purified using the Qiagen EndoFree maxi plasmid kit (www.qiagen.com).

3. In a separate tube, add $2 \mu 1$ Lipofectamine 2000 (Invitrogen, No. 11668-019, www.invitrogen.com) to $50 \mu \mathrm{l}$ Opti-Mem 1. Mix the tube gently by inverting, not by vortexing. Incubate the suspension for $5 \mathrm{~min}$ at room temperature without movement.

4. Combine the solution from step 2 with the suspension from step 3. Mix gently by inverting the tube and incubate for 20-25 min at room temperature to allow for formation of liposome complexes. Do not exceed a $30-\mathrm{min}$ incubation time. 

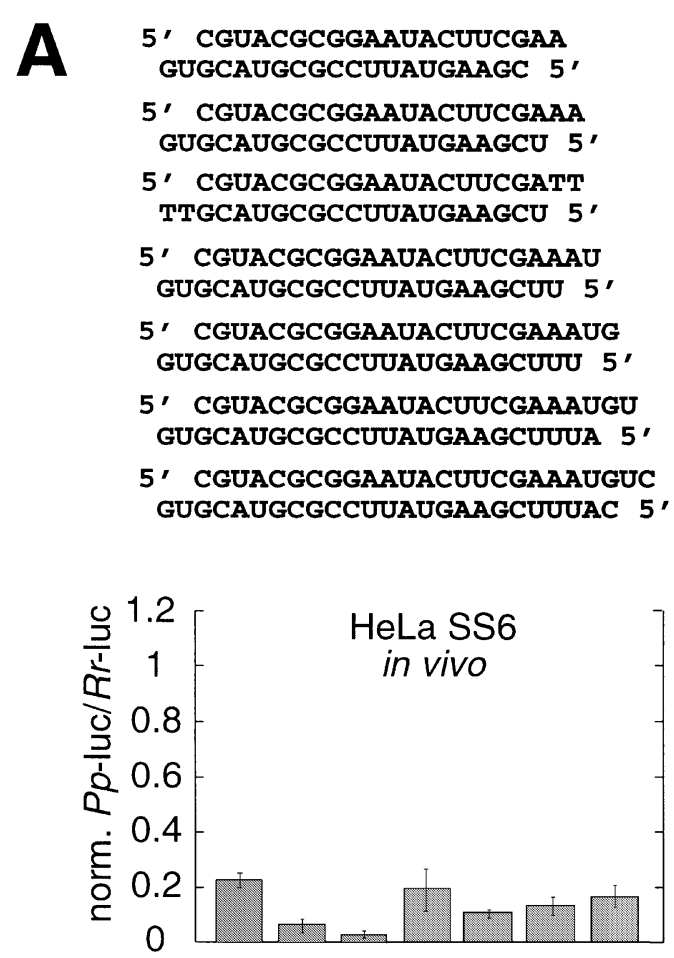

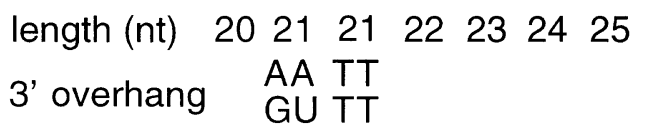

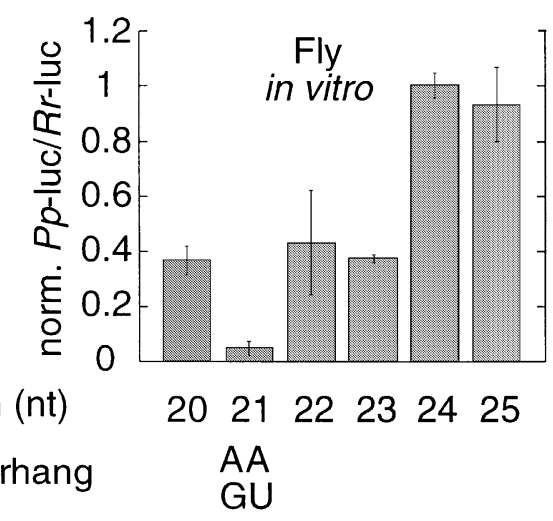

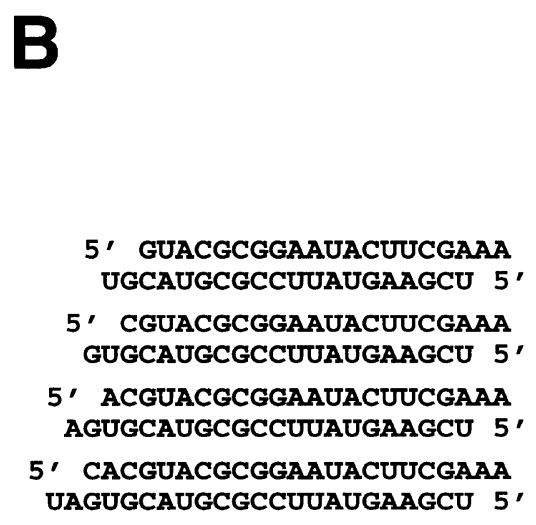
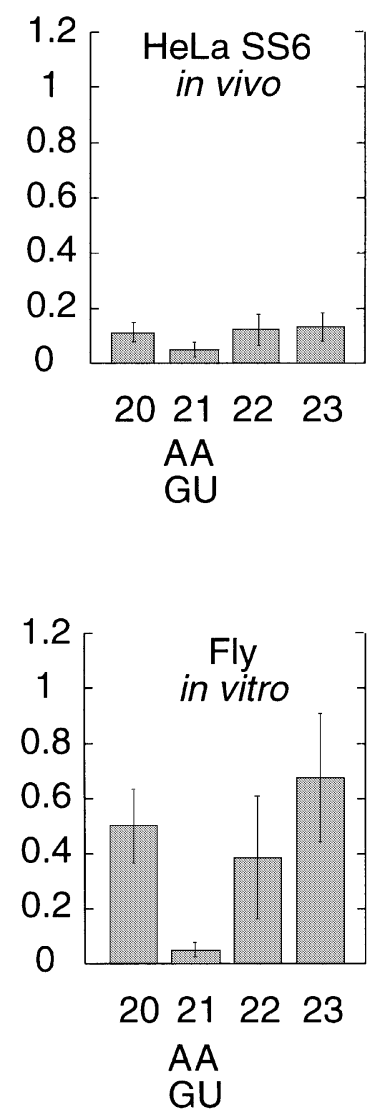

Fig. 5. Variation of the length of siRNA duplexes with preserved 2-nt $3^{\prime}$ overhangs. The siRNA duplexes were extended to the $3^{\prime}$ side of the sense siRNA (A) or the $5^{\prime}$ side of the sense siRNA (B). The siRNA duplex sequences and the respective interference ratios are indicated. For HeLa SS6 cells, siRNA duplexes $(0.84 \mu \mathrm{g})$ targeting GL2 luciferase were transfected together with pGL2-Control and pRL-TK plasmids (protocol 4). For comparison, the in vitro RNAi activities of siRNA duplexes tested in D. melanogaster lysate are indicated [23].

5. Add the liposome complexes to the well without replacing the growth medium and mix gently for $15 \mathrm{~s}$ by gently rocking the plate. Incubate the plate for $20-48 \mathrm{~h}$ at $37^{\circ} \mathrm{C}$ in the incubator (see above). If cytotoxic effects are to be expected from the transfection reagent, it is possible to change the growth medium $5 \mathrm{~h}$ after transfection.

6. To monitor luciferase activity, lyse cells and measure luciferase expression subsequently by the dual luciferase assay (Promega, No. E1960) according to the manufacturer's instructions.

Remark. To estimate the transfection efficiency it is convenient to cotransfect a GFP-coding plasmid together with $0.21 \mu \mathrm{g}$ of a siRNA duplex noncognate to GFP (e.g., invGL2, Fig. 4B) and to count the GFP-expressing cells by fluorescence microscopy. Transfection efficiencies for most cell lines described above range from 70 to $90 \%$. 


\section{Knockdown of the expression of endogenous genes by siRNA duplexes}

We examined silencing of many different genes expressed in cultured mammalian cells by duplexes of 21nt siRNAs [1,24]. Knockdown of proteins of various subcellular localizations, functions, or expression levels was achieved. The majority of knockdown experiments were performed in human HeLa cells, but we also knocked down proteins in SV40 transformed rat fibroblasts and mouse 3T3 cells. Knockdown of proteins was frequently associated with impaired cell growth or altered cell morphology, which was monitored by phasecontrast microscopy. If no alterations in cell growth or cell morphology were observed, immunofluorescence or Western blotting was performed to analyze the depletion of the target protein. When no antibodies are available, the levels of the targeted mRNA may be monitored by reverse transcription polymerase chain reaction (RTPCR) [25]. Examples of knockdown cells and characterization of the associated phenotypes are shown in Figs. 6-12.

Exogenous delivery of siRNA duplexes to mammalian cells was carried out with the transfection reagent Oligofectamine (Invitrogen, No. 12252-011, www.invitrogen.com), which was developed for the delivery of short oligonucleotides. Transfection efficiencies with Oligofectamine were near $90 \%$. A new siRNA transfection reagent, TransIT-TKO (Mirus, No. MIR 2150, www.genetransfer.com) has recently become available. Cells did not take up siRNA duplexes in the absence of transfection reagents. Knockdown phenotypes were apparent 1-3 days posttransfection, but depended on the efficiency of the siRNA duplex and/or the abundance and/or the lifetime (turnover) of the targeted proteins [24]. To control for the specificity of the knockdown, we transfected cultures with a siRNA duplex targeting firefly luciferase (GL2, Fig. 4B) or buffer, both of which have no detectable effect on cell growth or morphology.

\subsection{Protocol 5: transfection of siRNA duplexes}

The quantities of reagents given below are calculated for the transfection of one well of a 24-well plate.

1. The day before transfection, follow closely protocol 3 , but dilute the cell suspension after trypsination of the stock culture 1:10 rather than 1:5 before transferring to the 24-well plate. A higher dilution is necessary to obtain the recommended confluency of $50 \%$ for Oligofectamine transfection.

2. Mix $3 \mu \mathrm{l} 20 \mu \mathrm{M}$ siRNA duplex $(0.84 \mu \mathrm{g}, 60 \mathrm{pmol})$ with $50 \mu \mathrm{l}$ Opti-Mem 1.

3. In a separate tube, add $3 \mu$ l Oligofectamine or 3.5 $\mu \mathrm{l}$ of TransIT-TKO to $12 \mu \mathrm{l}$ Opti-Mem 1. Mix gently and incubate for 7-10 min at room temperature.

4. Combine the solutions prepared in steps 2 and 3 and mix gently by inversion, not by vortexing. Incubate for 20-25 $\mathrm{min}$ at room temperature to allow for formation of liposome complexes; the solution will turn turbid. Then add $32 \mu \mathrm{l}$ fresh Opti-Mem 1 to obtain a final volume of $100 \mu$ and mix gently by inversion. The addition of $32 \mu \mathrm{l}$ optiMEM is optional and serves only to adjust the total volume of cell culture medium to $600 \mu \mathrm{l}$ after transfection.

5. Add the 100- $\mu$ l liposome complexes to the well without replacing the growth medium and mix gently for $30 \mathrm{~s}$ by gently rocking the plate. Incubate the plate for 2-3 days at $37^{\circ} \mathrm{C}$ in the incubator.

\section{Detection of siRNA-mediated specific gene silencing}

Growth arrest of transfected cells is easily monitored by phase-contrast microscopy. Cells grown and transfected on coverslips are mounted on slides in Hepes-buffered DMEM ( $\mathrm{pH}$ 7.3) supplemented with $10 \%$ fetal calf serum (FCS) (Sigma, No. F-7521) and examined with a microscope for example equipped with a Plan-Neofluar $25 \times / 0.8$ objective. Cells arrested in mitosis round up and show condensed chromosomes while apoptotic cells have micronucleated, shriveled nuclei.

The preferred way of detecting specific gene knockdowns is to use a specific antibody recognizing the targeted gene product. Antibodies to many cellular proteins can be purchased commercially, for example, from Abcam (www.abcam.com), Novocastra (www.novocastra.co.uk), Progen (www.progen.com), Santa Cruz Biotechnology (www.scbt.com), Sigma (www.sigma-aldrich.com), and BD Transduction Laboratories (www.translab.com). As primary antibodies, murine monoclonal antibodies or rabbit polyclonal antibodies are commonly used. The concentration of primary antibodies is critical for the immunofluorescence assay as too strong immunofluorescence staining obstructs the quantification of the knockdown effect. Therefore, subsaturating concentrations of antibodies have to be used, which should be determined in a titration series. Monoclonal antibodies supplied as overgrown hybridoma supernatants are applied anywhere between 1:1 and 1:1000 dilutions. Monoclonal antibodies supplied as ascites fluid can often be diluted up to $1: 10,000$. Polyclonal antibodies should be used only after affinity purification. Secondary antibodies directed against IgGs of the primary mouse or rabbit antibody are best purchased as reagents coupled to fluorescent dyes such as fluorescein isothiocyanate (FITC), rhodamine, Cy3, Alexa 488 (Dianova, Hamburg, Germany, www.dianova.de; MolecularProbes, Eugene, OR, 
A

\begin{tabular}{ll}
$\begin{array}{l}\text { siRNA } \\
\text { duplex }\end{array}$ & $\begin{array}{l}\text { targeted } \\
\text { region }\end{array}$ \\
\hline
\end{tabular}

Lamin A/C $\quad 608-630$

5' CUGGACUUCCAGAAGAACATT
TTGACCUGAAGGUCUUCUUGU 5'

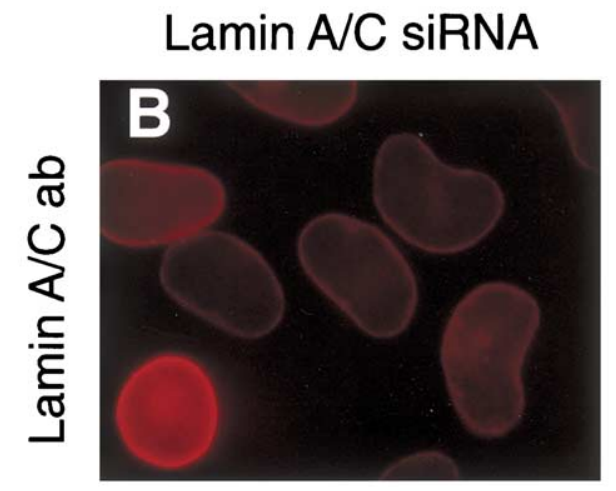

GL2 Pp-luc siRNA
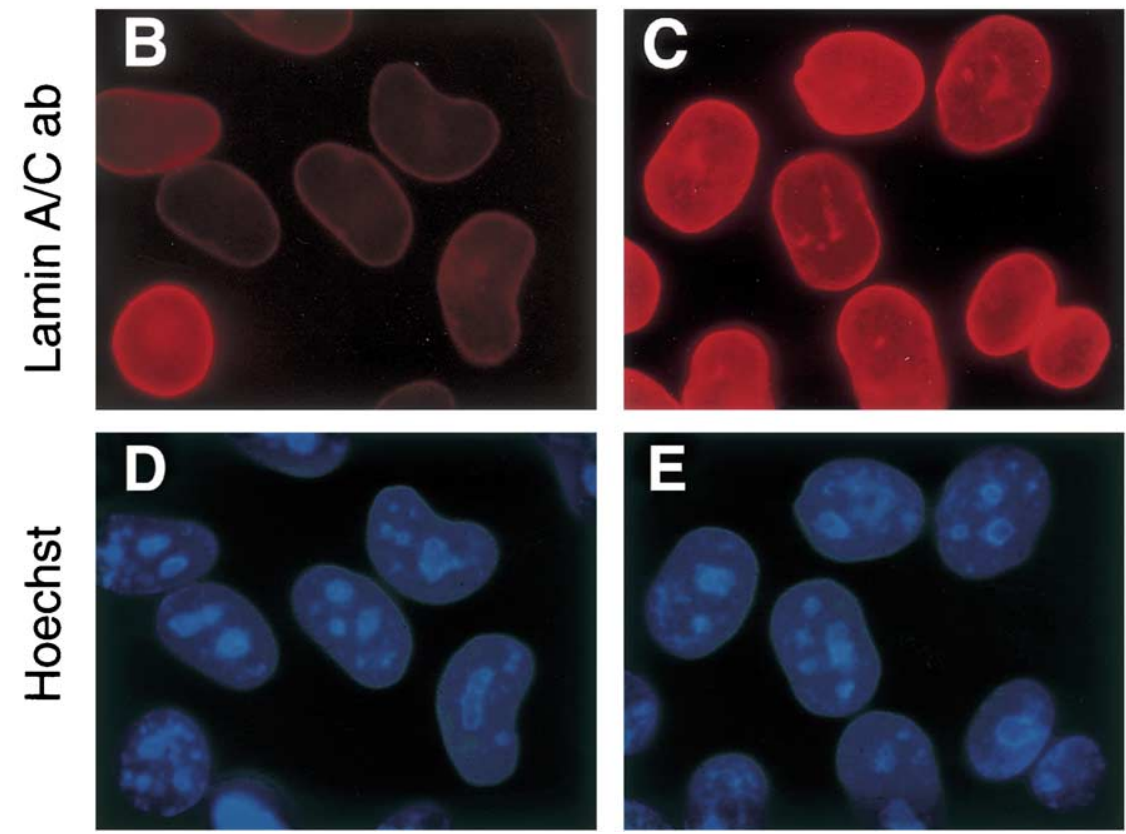

Fig. 6. Knockdown of lamin A/C protein. (A) Lamin A/C siRNA duplex. The targeted region of lamin A/C mRNA is indicated with respect to the start codon (pos. 1). HeLa SS6 cells were transfected with either lamin A/C siRNA (B, D) or GL2 Pp-luc control siRNA duplex (C, E) according to protocol 5. Knockdown of lamin A/C was monitored as described in protocol 6 using lamin A/C antibody 636 (Santa Cruz Biotechnology, No. sc7292; or Novocastra, No. NCL-LAM-A/C) The bright cell located at the bottom left-hand corner of (B) was not transfected.

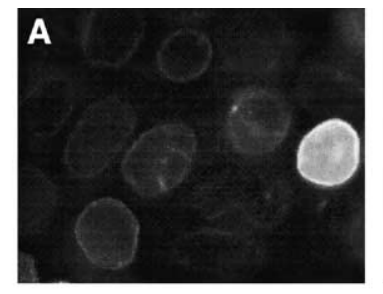

incubation days

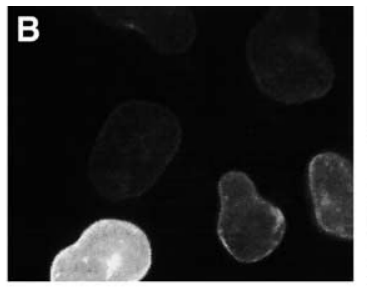

7

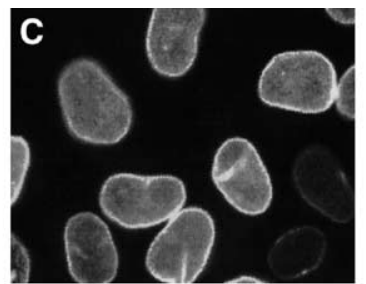

9

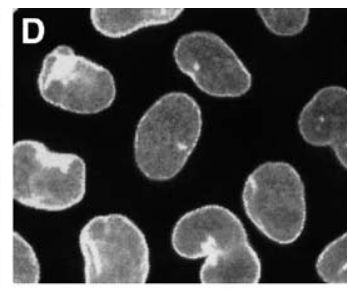

9 (control)

Fig. 7. Recovery of lamin A/C knockdown cells. HeLa SS6 cells were transfected with the lamin A/C siRNA duplex (protocol 5) and fixed and stained with lamin A/C-specific antibody at the indicated time points (protocol 6). (D) Cells transfected with a control GL2 luciferase siRNA duplex. Cells were split every second or third day to maintain exponential growth. Although the majority of cells has recovered from the knockdown 9 days posttransfection, a few cells still display reduced lamin A/C levels (C).

www.probes.com). The working conditions of the secondary antibodies are also established by titration series. Typical dilutions are between 1:40 and 1:100 for FITC- and rhodamine-conjugated antibodies, 1:600 for the Cy3-conjugated antibodies, and 1:100-1:200 for the Alexa-conjugated antibodies. It is also important to 


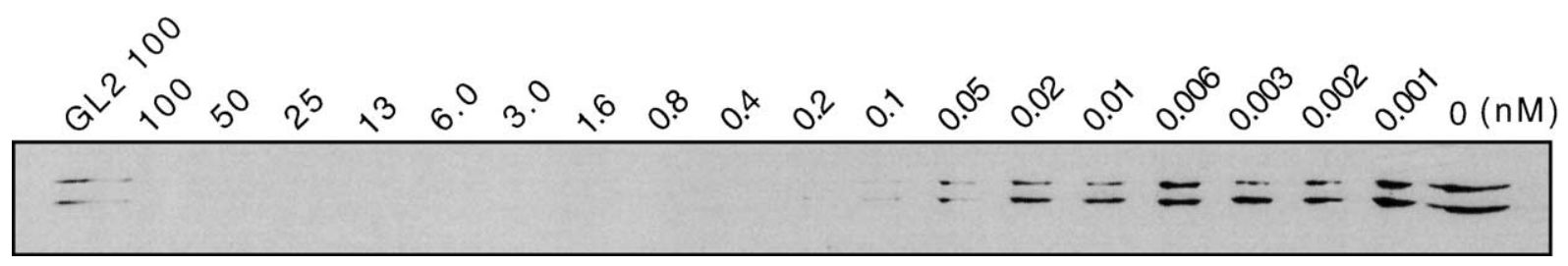

Fig. 8. Western blot analysis of HeLa SS6 cells transfected with various concentrations of lamin A/C siRNA duplex. Transfection of siRNA duplex was performed according to protocol 5 and the amount of duplex was varied from $0.84 \mu \mathrm{g}$ to $8.4 \mathrm{pg}$, which corresponds to a final duplex concentration in the medium of $100 \mathrm{nM}-1 \mathrm{pM}$, respectively. Cells transfected with buffer or $100 \mathrm{nM}$ GL2 Pp-luc siRNA duplex served as control. Western blotting was performed according to protocol 7.

A

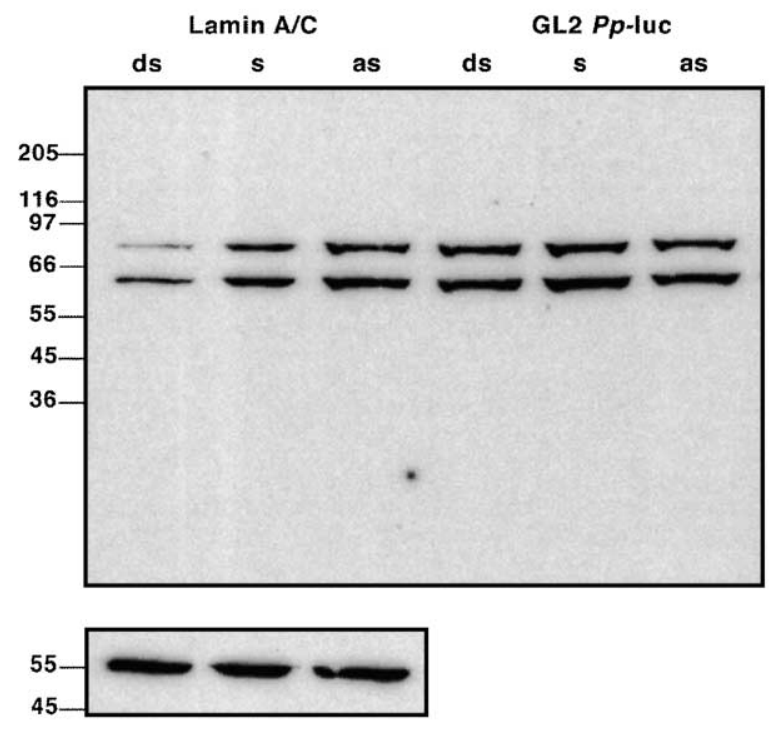

B

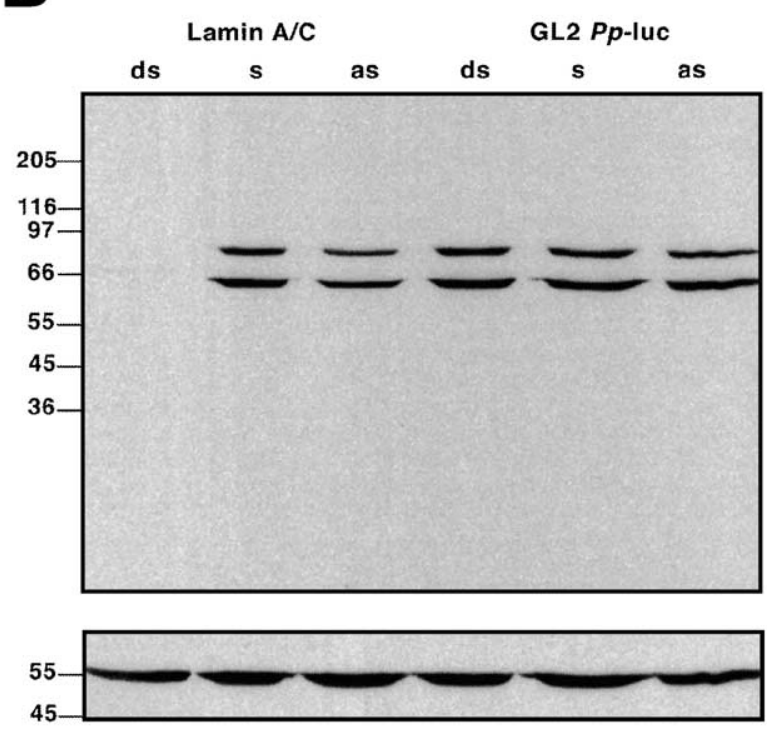

Fig. 9. Double-stranded siRNAs are required for gene silencing. HeLa SS6 cells were transfected with either duplex siRNA (ds) or single-stranded sense (s) or antisense (as) siRNA according to protocol 5. For transfection, $8.4 \mathrm{ng}$ (A) or $0.84 \mu \mathrm{g}$ (B) of sense, antisense, or dsRNA were used, which corresponds to 1 or $100 \mathrm{nM}$ final siRNA duplex concentration and 2 or $200 \mathrm{nM}$ single-stranded siRNA concentration. As nonspecific control, GL2 $P p$-luc siRNAs were used. Western blotting was performed according to protocol 7, harvesting cells 2 days posttransfection. Following lamin A/C detection by ECL, the blot was stripped and reprobed with vimentin antibody to control for loading (see bottom).

verify that the second antibody does not bind unless the primary antibody has bound first.

\subsection{Protocol 6: immunofluorescence detection of protein knockdowns}

1. Fix and permeabilize the knockdown cells. Methanol fixation is suitable for the detection of many cellular proteins, but the optimal fixation procedure may have to be established experimentally for each individual protein $[39,40]$. We recommend beginning tests with methanol fixation, which preserves the ultrastructure of the cell and sufficiently permeabilizes the cells for penetration of the antibody. Remove the coverslips carrying the knockdown cells (see protocol 5) from the 24-well plate with tweezers (Dumont No. 7). Place the coverslips on a ceramic rack and incubate in methanol chilled to $-10{ }^{\circ} \mathrm{C}$ for $6 \mathrm{~min}$.

2. Wash the methanol-fixed coverslips three times in phosphate-buffered saline (PBS: $137 \mathrm{mM} \mathrm{NaCl}, 7$ $\mathrm{mM} \mathrm{Na} 2 \mathrm{HPO}_{4}, 1.5 \mathrm{mM} \mathrm{KH} \mathrm{PO}_{4}, 2.7 \mathrm{mM} \mathrm{KCl}$, $\mathrm{pH}$ 7.1) and touch with filter paper to remove excess PBS. Place the coverslips in a wet chamber with cells facing up. A wet chamber is prepared by soaking filter paper in water and placing it into a $13-\mathrm{cm}$-diameter Petri dish. It is important that specimens do not dry out during the entire procedure.

3. Add $20 \mu \mathrm{l}$ of appropriately diluted primary antibody on top of the coverslip without touching the cells. Dilute antibodies with PBS buffer containing 0.5 $\mathrm{mg} / \mathrm{ml}$ BSA (Sigma, No. A-9706) and 0.02\% sodium azide. Make sure the solution is spread evenly over the entire surface of the coverslip. Transfer the 


\section{A}

SiRNA targeted

\section{Lamin A/C +} NuMA siRNAs
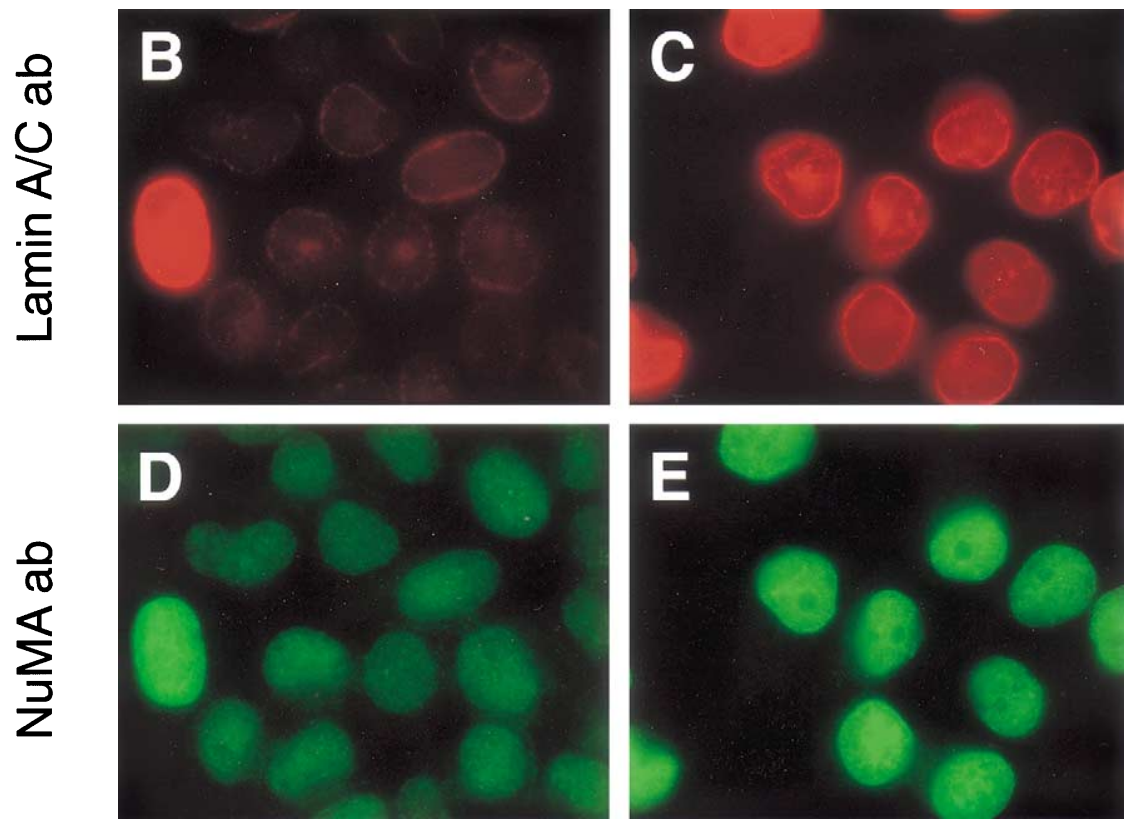

Fig. 10. Double knockdown of lamin A/C and NuMA in HeLa SS6 cells. (A) NuMA siRNA duplex. Cells transfected with $0.42 \mu \mathrm{g}$ lamin A/C and $0.42 \mu \mathrm{g}$ NuMA siRNA duplexes (B, D) and with $0.84 \mu \mathrm{g}$ of GL2 luciferase siRNA duplex control (C, E) according to protocol 5 . Two days after transfection, cells were examined with lamin A/C (B, C) or NuMA antibodies (D, E). Primary antibodies for lamin A/C (mouse monoclonal) and NuMA (affinity purified polyclonal [41]) were applied together, followed by simultaneous incubation of the secondary antibodies (Cy3 anti-mouse, Alexa 488 anti-rabbit) according to protocol 7. The majority of cells shows reduced expression of both target proteins; the single bright cell lighting up in (B) and (D) was nontransfected.

closed wet chamber to a $37{ }^{\circ} \mathrm{C}$ incubator and incubate for $45-60 \mathrm{~min}$.

4. Place the coverslips again on the ceramic rack and wash them three times for 5 min with PBS. Touch with filter paper to remove excess PBS and transfer the coverslips back to the wet chamber.

5. Add $20 \mu \mathrm{l}$ of appropriately diluted, fluorescently labeled secondary antibody. Incubate the wet chamber again for $45 \mathrm{~min}$ at $37^{\circ} \mathrm{C}$.

6. Repeat step 4.

7. Visualize the cell nuclei by chromatin staining. Add $20 \mu 11 \mu \mathrm{M}$ Hoechst 33342 (bisbenzimide, Serva No.
15091, www.serva.com) solution in PBS on top of the coverslip and incubate for $4 \mathrm{~min}$.

8. Repeat step 4.

9. Mount two coverslips per slide by placing the coverslips with the cells facing downward on a drop of Moviol mounting medium (Hoechst, www.hoechst.com). Place a piece of filter paper on top of the slide and press gently on top of the paper to remove excess mounting medium. Coverslips are glued to the slide using clear nail polish.

10. Examine immunofluorescence staining and take pictures using an upright light microscope, e.g., Zeiss 
A

\begin{tabular}{|c|c|c|}
\hline $\begin{array}{l}\text { siRNA } \\
\text { duplex }\end{array}$ & $\begin{array}{l}\text { targeted } \\
\text { region }\end{array}$ & sequence \\
\hline V1 & $346-368$ & $\begin{array}{l}\text { 5' CUACAUCGACAAGGUGCGCTT } \\
\text { TTGAUGUAGCUGUUCCACGCG }{ }^{5} \text {, }\end{array}$ \\
\hline V2 & $1145-1167$ & $\begin{array}{l}\text { 5' UACCAAGACCUGCUCAAUGTT } \\
\text { TTAUGGUUCUGGACGAGUUAC }{ }^{\prime} \text {, }\end{array}$ \\
\hline V3 & 863-885 & $\begin{array}{l}\text { 5' GAAUGGUACAAAUCCAAGUTT } \\
\text { TTCUUACCAUGUUUAGGUUCA }{ }^{\prime} \text {, }\end{array}$ \\
\hline V4 & $1037-1059$ & $\begin{array}{l}\text { 5, AUGGAAGAGAACUUUGCCGTT } \\
\text { TTUACCUUCUCUUGAAACGGC }\end{array}$ \\
\hline
\end{tabular}

B
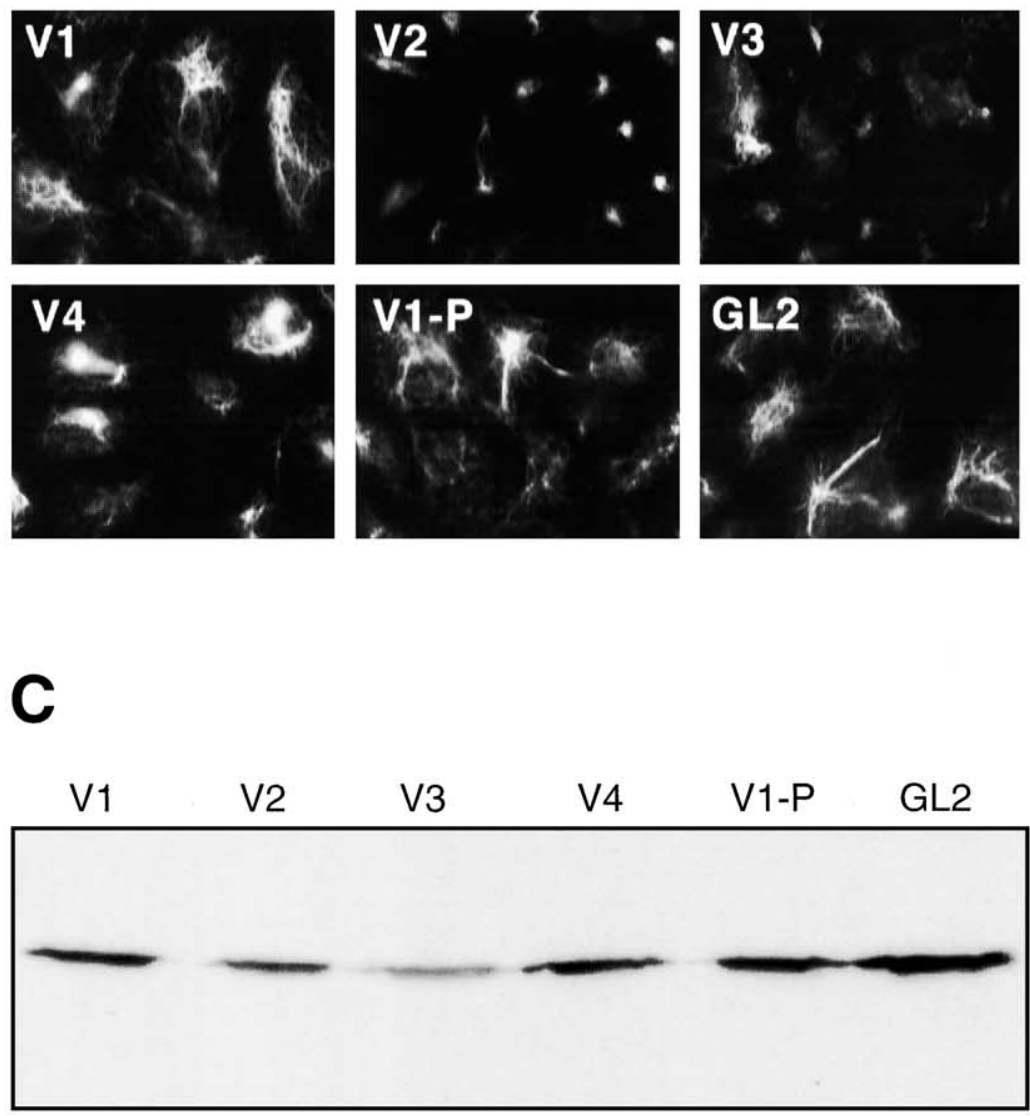

Fig. 11. Knockdown of the abundant cytoskeletal intermediate filament protein vimentin and comparison of the efficiency of different siRNA duplexes. (A) Sequences of vimentin siRNA duplex. (B) Immunofluorescence detection of vimentin 3 days posttransfection of HeLa SS6 cells. siRNA duplexes V1 and V4 are not efficient enough to suppress vimentin expression. 5'-Phosphorylation of siRNA duplex V1 (V1-P) has no effect. As control, transfection with GL2 luciferase siRNA duplex (GL2) was performed. Vimentin protein was detected with vimentin V9 antibody (Novocastra, No. NCL-VIM-V9) as described in protocol 6. (C) Western blot analysis of HeLa SS6 cells 3 days posttransfection with vimentin siRNA duplexes according to protocol 7. In agreement with the immunofluorescence results (B) V3 appears to be the most efficient siRNA duplex. Some of the residual vimentin has to be accounted for by incomplete transfection.

Axiophot with a F Fluar $40 \times / 1.30$ oil objective and MetaMorph Imaging Software (Universal Imaging Corp., West Chester, PA). Use identical exposure times for photographing the silenced and the control-treated cells. Alternatively, laser scanning microscopes may be used. 


\section{A}

$\begin{array}{ll}\text { siRNA } & \text { targeted } \\ \text { duplex } & \text { region }\end{array}$

Eg5
1547-1569
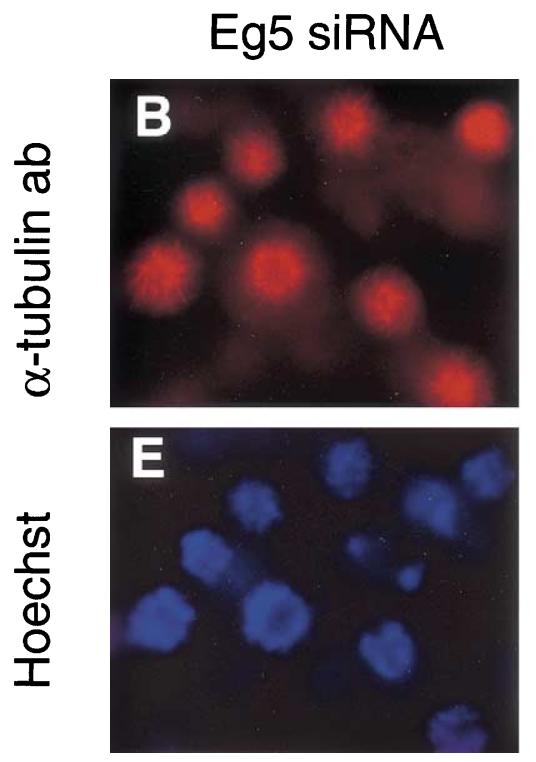
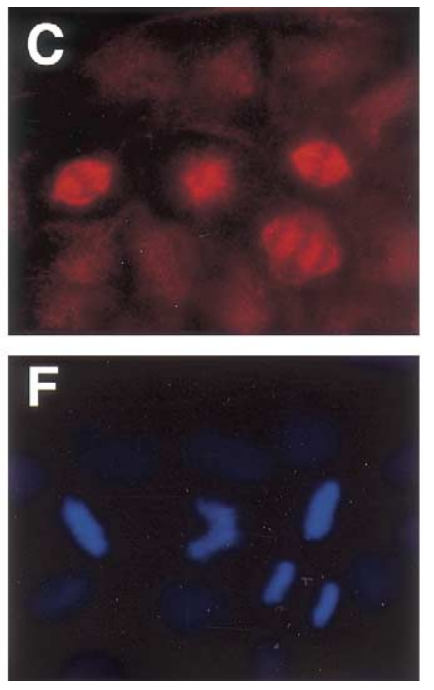

\section{5' CUGGAUCGUAAGAAGGCAGTT TTGACCUAGCAUUCUUCCGUC 5'}

sequence

GL2 Pp-luc siRNA
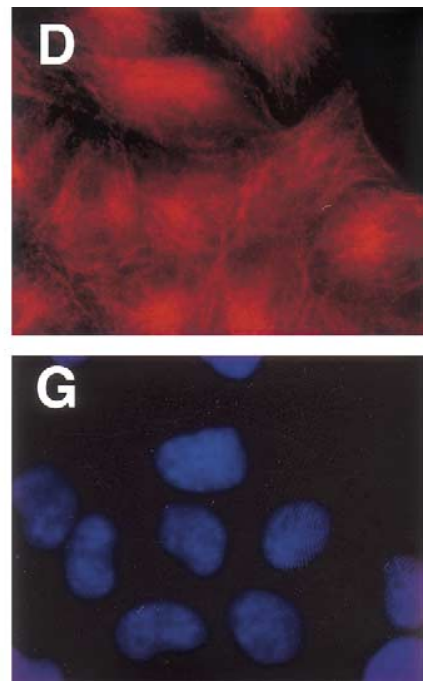

Fig. 12. Knockdown of the kinesin-related motor protein Eg5 causes mitotic defects. (A) Eg5 siRNA duplex. HeLa SS6 cells were transfected with Eg5 siRNA (B, E) or GL2 luciferase control siRNA duplexes (C, D, F, G). Two days posttransfection, spindle formation was analyzed by staining cells for $\alpha$-tubulin with $\alpha$-tubulin antibody (Sigma, No. T-9026) (B-D). Nuclear chromatin was stained with Hoechst dye (E-G). Eg5 siRNAs triggered aberrant mitotic arrest [24] with monoastral microtubular arrays (B). This phenotype was previously observed by alternative methods such as antibody microinjection [42] or application of the small molecule inhibitor monastrol [43]. In control experiments applying GL2 siRNAs, normal bipolar spindles were observed during mitosis $(C, F)$ or normal microtubules during interphase $(D, G)$.

\subsection{Protocol 7: detection of protein knockdown by Western blotting}

1. Remove the tissue culture medium from the siRNAtreated cells cultivated in 24-well plates. Rinse the cells once with $200 \mu \mathrm{l}$ PBS and add $200 \mu$ trypsinEDTA (Life Technologies, No. 25300-054). Incubate for $1 \mathrm{~min}$ at $37^{\circ} \mathrm{C}$, suspend the cells and add $800 \mu \mathrm{l}$ DMEM medium to quench the trypsin.

2. Transfer the suspended cells to a chilled $1.5-\mathrm{ml} \mathrm{mi-}$ crofuge tube. Collect the cells by centrifugation at $3000 \mathrm{rpm}(700 \mathrm{~g})$ for $4 \mathrm{~min}$ at $4{ }^{\circ} \mathrm{C}$. Resuspend the cell pellet in ice-cold PBS and centrifuge again.

3. Remove the supernatant and add $25 \mu$ of hot $(90$ $\left.{ }^{\circ} \mathrm{C}\right) 2 \times$ concentrated Laemmli sodium dodecyl sulfate (SDS) sample buffer (Bio-Rad, No. 161-073, www.bio-rad.com) to the cell pellet obtained from one well of a 24-well plate. Incubate the sample for $3 \mathrm{~min}$ in a boiling water bath and vortex.

4. Separate the proteins by SDS-polyacrylamide gel electrophoresis using an appropriate acrylamide concentration to resolve the appropriate molecular weight of the targeted protein [38]. We have separated proteins on minigels that were run at constant $10 \mathrm{~mA}$.

5. Transfer proteins onto nitrocellulose membrane (Protran BA85 $0.45 \mathrm{~mm}$, Schleicher \& Schuell, No. 10401196, www.s-und-s.de). Our minigels were electroblotted onto the membrane using a Bio-Rad Trans-Blot cell at $333 \mathrm{~mA}$ for $30 \mathrm{~min}$ in the cold room. As transfer buffer, $25 \mathrm{mM}$ Tris, $192 \mathrm{mM}$ glycine, $0.01 \%$ SDS, $20 \%$ methanol was used.

6. Verify the protein transfer by Ponceau S (Sigma) staining of the transfer membrane. 
7. Incubate the membrane in blocking solution $(5 \%$ milk powder in TBST $(0.2 \%$ Tween $20,20 \mathrm{mM}$ Tris- $\mathrm{HCl}, 150 \mathrm{mM} \mathrm{NaCl}, \mathrm{pH}$ 7.4)) for $1 \mathrm{~h}$ at $37^{\circ} \mathrm{C}$.

8. Replenish the blocking solution with fresh blocking solution and add the antibody in the appropriate dilution. Incubate $1-2 \mathrm{~h}$ at $37^{\circ} \mathrm{C}$.

9. Wash the blot four times with TBST for $10 \mathrm{~min}$.

10. For enhanced chemiluminescence (ECL) detection, incubate the blot with either horseradish peroxidase (HRP)-conjugated rabbit anti-mouse or HRP- conjugated swine anti-rabbit antibodies (Dako Diagnostika, Hamburg, Germany, www.dako.com) at a dilution of 1:20,000 as described in step 7 .

11. Repeat step 8 .

12. Perform ECL detection according to the protocol described by Amersham-Pharmacia (www.amersham.co.uk).

\section{Concluding remarks}

Small interfering RNAs (siRNAs) have become powerful reagents for triggering gene-specific silencing in mammalian cultured cells. siRNAs can be used to assess whether a gene is essential or nonessential, and specific gene silencing can be rapidly documented by immunofluorescence microscopy or Western blotting provided that specific antibodies to the targeted proteins are available. Silencing persists for several cell generations and even major cellular proteins such as vimentin have been knocked down. Simultaneous knockdown of two different proteins in the same cell population is possible. The highly efficient siRNA duplexes provide a novel tool for genomewide analysis of gene function in mammalian cells and may become useful for therapeutic applications.

\section{Acknowledgments}

We thank M. Osborn and D.J. Arndt-Jovin for reagents, M. Osborn, T. Achsel, R. Rauhut, J. Martinez, A. Patkaniowska, M. Hoßbach, and M. Mitkowski for critical comments on the manuscript, and W. Lendeckel and H.-J. Dehne for technical assistance.

\section{References}

[1] S.M. Elbashir, J. Harborth, W. Lendeckel, A. Yalcin, K. Weber, T. Tuschl, Nature 411 (2001) 494-498.

[2] N.J. Caplen, S. Parrish, F. Imani, A. Fire, R.A. Morgan, Proc. Natl. Acad. Sci. USA 98 (2001) 9742-9747.

[3] A. Fire, S. Xu, M.K. Montgomery, S.A. Kostas, S.E. Driver, C.C. Mello, Nature 391 (1998) 806-811.

[4] M.K. Montgomery, S. Xu, A. Fire, Proc. Natl. Acad. Sci. USA 95 (1998) 15502-15507.

[5] R.W. Carthew, Curr. Opin. Cell Biol. 13 (2001) 244-248.
[6] S.M. Hammond, A.A. Caudy, G.J. Hannon, Nat. Rev. Genet. 2 (2001) 110-119.

[7] P.A. Sharp, Genes Dev. 15 (2001) 485-490.

[8] T. Tuschl, ChemBioChem 2 (2001) 239-245.

[9] P.M. Waterhouse, M.B. Wang, T. Lough, Nature 411 (2001) 834-842.

[10] P.D. Zamore, Nat. Struct. Biol. 8 (2001) 746-750.

[11] M.J. Clemens, A. Elia, J. Interferon Cytokine Res. 17 (1997) 503-524.

[12] G.R. Stark, I.M. Kerr, B.R. Williams, R.H. Silverman, R.D. Schreiber, Annu. Rev. Biochem. 67 (1998) 227-264.

[13] M. Kumar, G.G. Carmichael, Microbiol. Mol. Biol. Rev. 62 (1998) 1415-1434.

[14] G. Geiss, G. Jin, J. Guo, R. Bumgarner, M.G. Katze, G.C. Sen, J. Biol. Chem. 276 (2001) 30178-30182.

[15] V. Bitko, S. Barik, BMC Microbiol. 1 (2001) 34.

[16] S.M. Elbashir, W. Lendeckel, T. Tuschl, Genes Dev. 15 (2001) $188-200$.

[17] E. Bernstein, A.A. Caudy, S.M. Hammond, G.J. Hannon, Nature 409 (2001) 363-366.

[18] R.F. Ketting, S.E. Fischer, E. Bernstein, T. Sijen, G.J. Hannon, R.H. Plasterk, Genes Dev. 15 (2001) 2654-2659.

[19] E. Billy, V. Brondani, H. Zhang, U. Muller, W. Filipowicz, Proc. Natl. Acad. Sci. USA 98 (2001) 14428-14433.

[20] L. Cerutti, N. Mian, A. Bateman, Trends Biochem. Sci. 25 (2000) $481-482$.

[21] S.M. Hammond, S. Boettcher, A.A. Caudy, R. Kobayashi, G.J. Hannon, Science 293 (2001) 1146-1150.

[22] S.M. Hammond, E. Bernstein, D. Beach, G.J. Hannon, Nature 404 (2000) 293-296.

[23] S.M. Elbashir, J. Martinez, A. Patkaniowska, W. Lendeckel, T. Tuschl, EMBO J. 20 (2001) 6877-6888.

[24] J. Harborth, S.M. Elbashir, K. Bechert, T. Tuschl, K. Weber, J. Cell Sci. 114 (2001) 4557-4565.

[25] G. Hutvágner, J. McLachlan, É. Bálint, T. Tuschl, P.D. Zamore, Science 93 (2001) 834-838.

[26] J.E. Garrus et al., Cell 107 (2001) 55-65.

[27] N. Ancellin, C. Colmont, J. Su, Q. Li, N. Mittereder, S.S. Chae, S. Steffansson, G. Liau, T. Hla, J. Biol. Chem. 10 (2001) 10.

[28] X. Bai, D. Zhou, J.R. Brown, B.E. Crawford, T. Hennet, J.D. Esko, J. Biol. Chem. 276 (2001) 48189-48195.

[29] D. Cortez, S. Guntuku, J. Qin, S.J. Elledge, Science 294 (2001) 1713-1716.

[30] L. Li, J. Mao, L. Sun, W. Liu, D. Wu, J. Biol. Chem. 12 (2001) 12.

[31] L.M. Martins et al., J. Biol. Chem. 277 (2002) 439-444.

[32] P.D. Good et al., Gene Ther. 4 (1997) 45-54.

[33] J. Ohkawa, K. Taira, Hum. Gene Ther. 11 (2000) 577-585.

[34] A. Nykänen, B. Haley, P.D. Zamore, Cell 107 (2001) 309-321.

[35] J.R. Masters et al., Proc. Natl. Acad. Sci. USA 98 (2001) 8012-8017.

[36] F. Eckstein, Oligonucleotides and Analogues, second ed., Oxford University Press, Oxford, UK, 1991.

[37] M.L. Deras, K. Vandenburgh, S.A. Scaringe, submitted.

[38] J. Sambrook, E. Fritsch, T. Maniatis, Molecular Cloning, second ed., Cold Spring Harbor Laboratory Press, Plainview, NY, 1989.

[39] D.L. Spektor, R.D. Goldman, L.A. Leinwand, Cells: A Laboratory Manual, Cold Spring Harbor Laboratory Press, Plainview, NY, 1989.

[40] J.E. Celis, Cell Biology: A Laboratory Handbook, vol. 2, Academic Press, San Diego, CA, 1998.

[41] J. Harborth, J. Wang, C. Gueth-Hallonet, K. Weber, M. Osborn, EMBO J. 18 (1999) 1689-1700.

[42] A. Blangy, H.A. Lane, P. d'Herin, M. Harper, M. Kress, E.A. Nigg, Cell 83 (1995) 1159-1169.

[43] T.U. Mayer, T.M. Kapoor, S.J. Haggarty, R.W. King, S.L. Schreiber, T.J. Mitchison, Science 286 (1999) 971-974. 